\title{
An audit tool for longitudinal assessment of the health-related characteristics of urban neighborhoods: implementation methods and reliability results
}

Madhumita Ghosh-Dastidar ${ }^{1 *}$, Gerald P. Hunter ${ }^{2}$, Jennifer C. Sloan³ ${ }^{3}$ Rebecca L. Collins ${ }^{1}$, Andrea S. Richardson², Wendy Troxel $^{2}$, Natalie Colabianchi ${ }^{4}$ and Tamara Dubowitz ${ }^{2}$

\begin{abstract}
Background: Improving the neighborhood environment may help address chronic disease and mortality. To identify neighborhood features that are predictors of health, objective assessments of the environment are used. Multiple studies have reported on cross-sectional assessments of health-related neighborhood features using direct observation. As study designs expand to better understand causation and predictors of change, there is a need to test whether direct observation methods are adequate for longitudinal assessment. To our knowledge, this is the first study to report on the reliability of repeated measurements of the neighborhood environment, and their stability, over time.
\end{abstract}

Methods: The Pittsburgh Hill/Homewood Research on Neighborhood Change and Health (PHRESH) study conducted longitudinal assessments in two low-income, African American neighborhoods at three waves (years 2012, 2015, 2017). The PHRESH audit tool is a modification of earlier validated tools, with an emphasis on environment features relevant for physical activity, sleep, and obesogenic behaviors. Trained data-collector pairs conducted direct observations of a $25 \%$ sample of street segments in each neighborhood. At each wave, we audited a sub-sample of street segments twice and assessed reliability using percentage inter-observer agreement and krippendorf's alpha statistics. Stability of these items was assessed as exhibiting moderate or high agreement at every time point.

Results: Across waves, a majority (81\%) of the items consistently demonstrated moderate to high agreement except for items such as public/communal space, amount of shade, sidewalk features, number of traffic lanes, garden/flower bed/planter, art/statue/monument, amount of trash, and physical disorder. The list of items with poor agreement includes features that are easy to miss (e.g. flower bed/planter), hard to assess from outside (e.g. public/communal space), or may change quickly (e.g. amount of trash).

(Continued on next page)

\footnotetext{
* Correspondence: bonnieg@rand.org

${ }^{1}$ RAND Corporation Santa Monica, 1776 Main St, Santa Monica, CA 90401

USA

Full list of author information is available at the end of the article
}

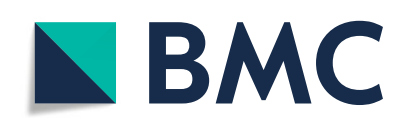

(- The Author(s). 2020 Open Access This article is licensed under a Creative Commons Attribution 4.0 International License, which permits use, sharing, adaptation, distribution and reproduction in any medium or format, as long as you give appropriate credit to the original author(s) and the source, provide a link to the Creative Commons licence, and indicate if changes were made. The images or other third party material in this article are included in the article's Creative Commons licence, unless indicated otherwise in a credit line to the material. If material is not included in the article's Creative Commons licence and your intended use is not permitted by statutory regulation or exceeds the permitted use, you will need to obtain permission directly from the copyright holder. To view a copy of this licence, visit http://creativecommons.org/licenses/by/4.0/. The Creative Commons Public Domain Dedication waiver (http://creativecommons.org/publicdomain/zero/1.0/) applies to the data made available in this article, unless otherwise stated in a credit line to the data. 
(Continued from previous page)

Conclusion: In this paper, we have described implementation methods, reliability results and lessons learned to inform future studies of change. We found the use of consistent methods allowed us to conduct reliable, replicable longitudinal assessments of the environment. Items that did not exhibit stability are less useful for detecting real change over time. Overall, the PHRESH direct observation tool is an effective and practical instrument to detect change in the neighborhood environment.

Keywords: Audit tool, Built environment, Direct observation, Longitudinal assessment, Neighborhood environment, Reliability

\section{Background}

Neighborhoods are important for health [1-4]. In fact, the neighborhood environment has been linked to multiple health outcomes including sleep, mental health, cardiovascular risk, and mortality [5-9]. Certain features (e.g. sidewalks) may directly encourage active transportation and physical activity [10-15] and others (e.g. street lighting, noise) may impact sleep [16-18], which, in turn, may influence chronic diseases $[19,20]$. Residents of low-income and racially/ethnically segregated neighborhoods share a disproportionate burden of chronic disease [21], as well as limited access to resources, which could contribute to poor health [22-24]. Improving the neighborhood environment holds promise for addressing health-related behaviors associated with chronic disease and mortality [25].

Micro or granular features of the neighborhood (e.g. street lighting) may affect residents' experiences more directly than macro-level features (e.g. residential density), thus providing stronger links with health behaviors [26-28]. Also, micro-level features are more easily modified than macro-level features. For example, it takes less time and money to repair a sidewalk than to change the land-use mix of a community. While there are multiple approaches for collecting detailed assessments of micro-features of neighborhoods [29-34], direct observation using audit tools is the preferred approach because it allows for systematic observation of detailed or granular features [27]. Google Street View (GSV) has been increasingly used to observe the built environment and provides a cheaper alternative to direct observation (Clarke et al., 2010; Taylor et al., 2011) [35, 36]. While GSV has demonstrated reliability when assessing certain features of the environment (including types of land use, slope, cycling lane or gathering places), it has certain limitations. Its reliability was not as high when considering detailed features, such as the presence of litter or vacant dwellings, and when making qualitative observations such as the quality of sidewalk or housing (Clarke et al., 2010) [35]. Also, GSV imagery is not available for every street in the U.S. and is updated irregularly (Clarke et al., 2010) [35]. Mixed findings regarding the relationship between micro features of the environment and health outcomes could be due to differences in measurement approaches across studies. An increased interest in the local environment for public policy has led to increased emphasis on the rigorous development, implementation and validation of audit tools for direct observation.

In a comprehensive review, Brownson et al. (2009) [27], described multiple audit tools for direct observation of the physical environment [27]. These tools shared some common content including one or more measures of: land use (e.g., presence and type of housing); streets and traffic (e.g., traffic volume); sidewalks; bicycling facilities; public space/amenities (e.g., presence of benches); architecture or building characteristics (e.g., building height); parking and driveways (e.g., parking garage); maintenance (e.g., litter); and indicators of safety (e.g., graffiti). Other features less consistently assessed are noise levels, or health promotion supports (e.g., billboards promoting physical activity) [27]. Existing audit tools have been used for one-time examinations of the neighborhood environment. As designs expand to better understand causation and predictors of change, there is a need to test whether audit tools are adequate for longitudinal assessment.

The Pittsburgh Hill/Homewood Research on Neighborhood Change and Health (PHRESH) study leverages a natural experiment design, comparing an intervention and a control neighborhood, to evaluate whether neighborhood improvements benefit residents' health $[8,24$, 37]. Between 2011 and 2018, the intervention neighborhood received about $\$ 200$ million, while the comparison neighborhood received approximately $\$ 48$ million, in publicly-funded investments. Efforts involved physical infrastructure modification (i.e., street lengths, street names, traffic patterns) and construction of streets, housing and landscaping. To systematically document change, we conducted multiple direct observations of the neighborhood environment over a 5-year period with an emphasis on features that may impact physical activity or sleep.

Of the existing audit tools, four were comparable to ours with respect to detail, content and data collection 
approach: Systematic Pedestrian and Cycling Environmental Scan (SPACES) [38]; St. Louis Analytic Audit Tool and Checklist (SLU) [39, 40]; Systematic Social Observation protocol [29] and Pedestrian Environment Data Scan (PEDS) [41]. Two of these studies reported that $70 \%$ of items had kappa statistics [42] above .40, one reported average reliability of .87 , while the fourth study reported high inter-observer agreement of $75 \%$ or greater [27]. Longitudinal studies may encounter pitfalls if these audit tools are not reliable over time. Mismeasurement can obscure meaningful differences, while systematic bias can produce spurious findings. In this paper, we describe the implementation methods, lessons learned, and stability of reliability estimates from PHRE $\mathrm{SH}$ longitudinal assessments of the neighborhood environment at three time points over a five-year period. Our findings can help inform future studies of changes in the built and social environment.

\section{Methods}

\section{Context}

PHRESH is an ongoing study of two low-income and predominantly African American communities in Pittsburgh, PA chosen because of their similarities. Hill District is approximately 1.37 mile $^{2}$ with population of approximately 10,000; while Homewood is 1.45 mile $^{2}$ with population of approximately 8000 . Both are residential neighborhoods. We were examining features of the built and social environment that correlate with health, as well as documenting to what extent changes impact residents' health and well-being, diet, exercise, sleep, heart, and cognitive health. The PHRESH study follows a cohort of individuals and their surrounding physical and social environment to evaluate these questions. Details of the study design have been described elsewhere [43, 44]. To systematically measure change, we conducted assessments of the environment at three timepoints (2012, 2015 and 2017). We modified the Bridging the Gap/Community Obesity Measures Project (BTG-COMP) Street Segment Observation form [4547], which draws from validated instruments used by other major studies assessing neighborhood features correlated with walking and physical activity [38, 40, 41, 48-50]. All study protocols were approved by the organization's Institutional Review Board.

\section{Audit tool}

The PHRESH Street Segment Audit (SSA) tool is a detailed assessment of neighborhood-level physical and social features related to health behaviors, with an emphasis on physical activity and sleep. As seen in Table 1, our tool includes (i) Land use mix capturing diversity of land use, (ii) Physical activity (PA) facility to include spaces for play or physical activity; (iii) Walking/
Table 1 PHRESH Street Segment Audit (SSA) Items

\begin{tabular}{|c|c|c|}
\hline $\begin{array}{l}\text { Audit tool } \\
\text { section }\end{array}$ & $\begin{array}{l}\text { Number of } \\
\text { items }\end{array}$ & Sample items \\
\hline Land use mix & 14 & $\begin{array}{l}\text { Housing, public/civic, } \\
\text { office, retail, recreational, } \\
\text { vacant. }\end{array}$ \\
\hline Environment & 6 & $\begin{array}{l}\text { Slope, slight or steep hill, } \\
\text { number of trees, shade } \\
\text { from trees, bars on or } \\
\text { broken/boarded windows }\end{array}$ \\
\hline $\begin{array}{l}\text { Physical activity } \\
\text { facility }\end{array}$ & 8 & $\begin{array}{l}\text { Indoor facility, park, playing field, playing } \\
\text { court, trail }\end{array}$ \\
\hline $\begin{array}{l}\text { Walking/cycling } \\
\text { environment }\end{array}$ & 20 & $\begin{array}{l}\text { Street type, vehicular lanes, } \\
\text { traffic features, bike lanes, } \\
\text { sidewalks }\end{array}$ \\
\hline Safety signs & 5 & $\begin{array}{l}\text { Bicycle or pedestrian crossing, } \\
\text { kids at play, special speed limit }\end{array}$ \\
\hline $\begin{array}{l}\text { Amenities and } \\
\text { litter }\end{array}$ & 16 & $\begin{array}{l}\text { Neighborhood or community } \\
\text { sign, garden/flower bed/planter, } \\
\text { art/statue/monument, benches, } \\
\text { drinking fountains, bus stops, } \\
\text { trash, perceived safety while } \\
\text { walking, attractiveness of street } \\
\text { segment for walking }\end{array}$ \\
\hline $\begin{array}{l}\text { Gathering } \\
\text { places }\end{array}$ & 11 & $\begin{array}{l}\text { Restaurants, libraries, } \\
\text { barbershops, churches, } \\
\text { bars, corner stores }\end{array}$ \\
\hline Social disorder & 8 & $\begin{array}{l}\text { Presence of police or security guard, adults } \\
\text { loitering, loud music, } \\
\text { people smoking }\end{array}$ \\
\hline Noise pollution & 1 & Level of noise pollution \\
\hline $\begin{array}{l}\text { Physical } \\
\text { disorder }\end{array}$ & 8 & $\begin{array}{l}\text { Broken bottles, drug } \\
\text { paraphernalia, graffiti, } \\
\text { broken windows }\end{array}$ \\
\hline
\end{tabular}

cycling environment including presence of sidewalks, shoulders and bike lanes; (iv) Safety signs including traffic calming and control features; (iv) Amenities and litter including features that make a segment appealing and pedestrian friendly, as well as two subjective assessments (perceived safety of walking; perceived attractiveness for walking) to complement the objective assessments. To the existing BTG-COMP audit tool, we added Environment (e.g. trees, cliffs/ravines) and Gathering places (e.g. restaurants, barbershop, church). In the last data collection round (2017), we also added Social disorder items (e.g. presence of police, people selling illegal drugs); a single item on Noise pollution and Physical disorder items (e.g. amount of beer or liquor bottles, abandoned cars), as they have been shown to be related to health behaviors such as sleep [51-53]. See Supplemental Table 1 for a full list of items.

\section{Street segment selection}

The two neighborhoods are residential with almost no arterial segments. Due to homogeneity among street segments within a concentrated geographic area and to 
reduce costs, we audited a random, representative sample from each of the study neighborhoods. To draw a representative sample, we constructed a complete listing $(n=2027)$ including all segments within a quarter mile of the neighborhood boundaries. The listing was compiled using a geographic shapefile provided by ESRI (ESRI, 2011), and was supplemented with street network information provided by city of Pittsburgh's GIS department, Google Maps, and personal inspection. The decision to draw a random $25 \%$ sample was informed by an earlier published study [54]. Therefore, 511, 585 and 586 segments were sampled in 2012, 2015 and 2017, respectively.

Whenever possible, a street segment was followed over time. The planned change in the study neighborhoods affected the nature and existence of some streets. We saw significant changes in areas with public housing (often old, dating back decades). Between 2011 and 2018, \$136.5 million and $\$ 54.3$ million in residential development (including some HOPE VI grants) came into the Hill District and Homewood, respectively. In and around public housing, entire street blocks were demolished; in certain areas, the street grids themselves changed. There were about five areas where street networks themselves changed (not just the buildings on the streets), with the changes shown in Fig. 1. Thus, we had to establish consistent rules to address such changes. Specifically, if a sampled segment did not exist at a follow up wave, a randomly selected segment from the same neighborhood served as replacement. If a sampled segment was bisected, both parts were included. If a segment was lengthened, the new attributes (including revised length) of the segment were recorded for follow up audits.

\section{Data collection}

All data collectors were community members familiar with the neighborhoods, and some of the data collectors participated in two waves $(2015,2017)$ of data collection. Training was conducted by an experienced trainer and
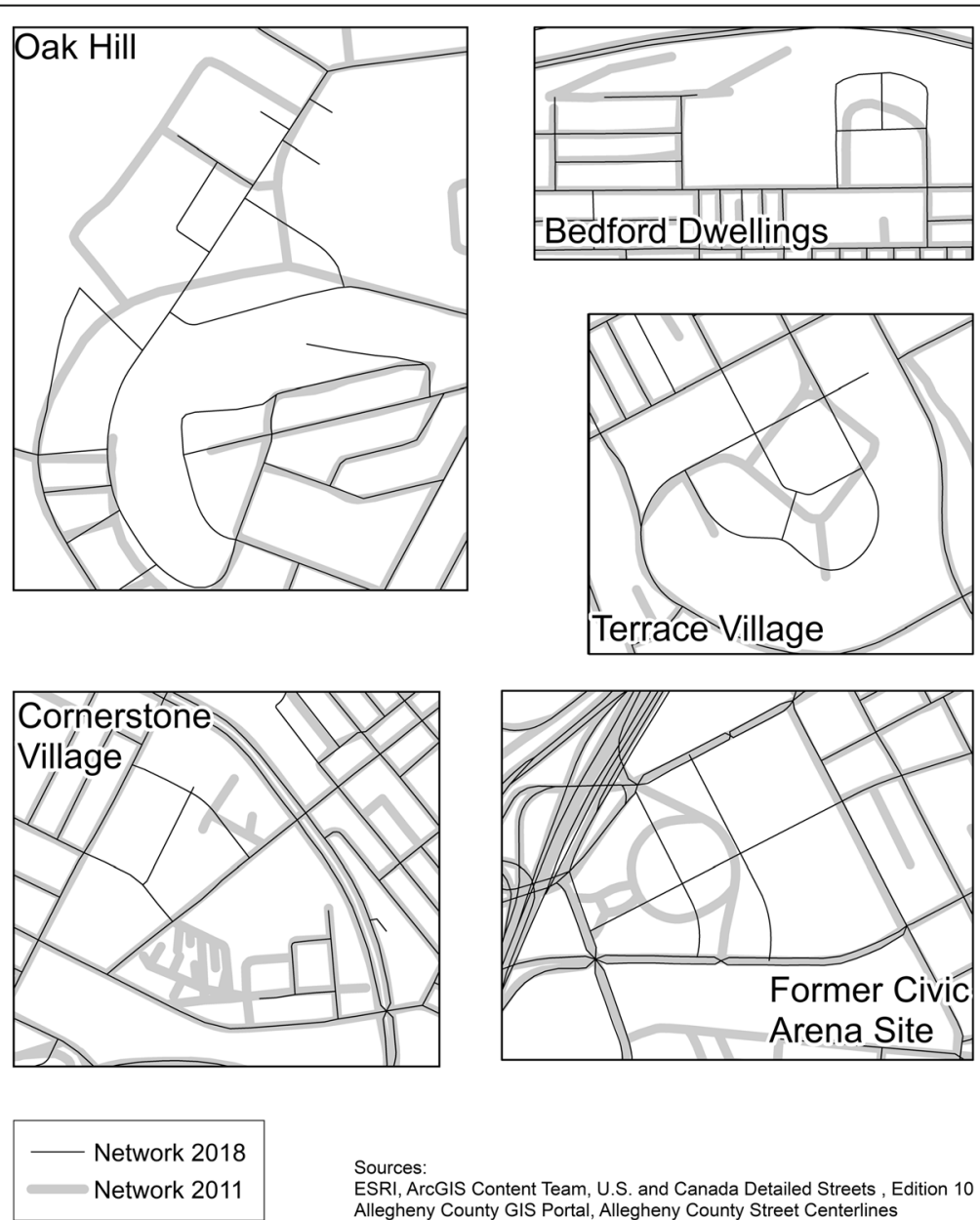

Sources:

ESRI, ArcGIS Content Team, U.S. and Canada Detailed Streets, Edition 10 Allegheny County GIS Portal, Allegheny County Street Centerlines

Fig. 1 Changing Street Networks. Source: ESRI, ArcGIS Content Team, U.S. and Canada Detailed Streets, Edition 10 Allegheny County GIS Portal, Allegheny County Street Centerlines 
consisted of three parts: (i) in-class presentations including examples and photographs (Fig. 2) with discussions about highlighted characteristics to look for; (ii) field practice on 'live' street segments around the training site; and (iii) a certification exercise where the data collectors and the trainer independently rated the same street segment, and compared ratings to test the data collector's understanding of the tool, observation skills, and data recording technique. Data collectors were given a comprehensive manual with the safety protocol and detailed description of audit tool items accompanied with photo examples (Fig. 3), and a summary sheet responding to common questions asked (e.g. FAQ). Each street segment was audited by a team of two data collectors (hereafter, DC pair), which is shown to improve reliability of ratings [41]. The DC pair walked the street segments together and made a single joint rating for each item, with discussions to resolve disagreements about proposed ratings in real time. A field coordinator oversaw data collection and assigned data collectors to street segments using maps. In each year, audits were conducted between August and October.

\section{Reliability testing}

A random sub-sample of the full sample of street segments, selected for direct observation, was subject to reliability testing ( $n=60$ in 2012, 2015; $n=100$ in 2017).
We drew a sub-sample of about $10 \%$ because it was considered reasonable from both a cost and calculation standpoint. While there were not enough segments in the sub-sample to test reliability in the separate neighborhoods, we were able to look at overall reliability if we pooled them together. Each segment in the reliability sub-sample was audited twice within a one-week period. Different DC pairs conducted the two ratings, so that no individual rated the same segment twice. The two ratings were also matched on day and time in 2017 because these factors were considered important for the new physical and social disorder items (see Table 1) added to the 2017 audit tool. Our reliability statistics were chosen to accommodate the response categories used in the SSA tool. About half the items had three response categories ("neither", "either", "both sides of the street"), while the rest were mostly binary noting whether a feature was present or absent in that street segment. A few items (e.g. physical disorder) had more than three response categories (e.g. none, a few [1-3], some [4-6], a lot (7 or more)).

Reliability analysis included calculation of prevalence, percentage inter-observer agreement (hereafter, $\mathrm{PO}$ ) [55, 56] and krippendorff's alpha (hereafter, KA) [57-60]. Reliability statistics including KA are sensitive to base or prevalence rates. Therefore, while the KA is more rigorous and indicates whether agreement exceeded chance
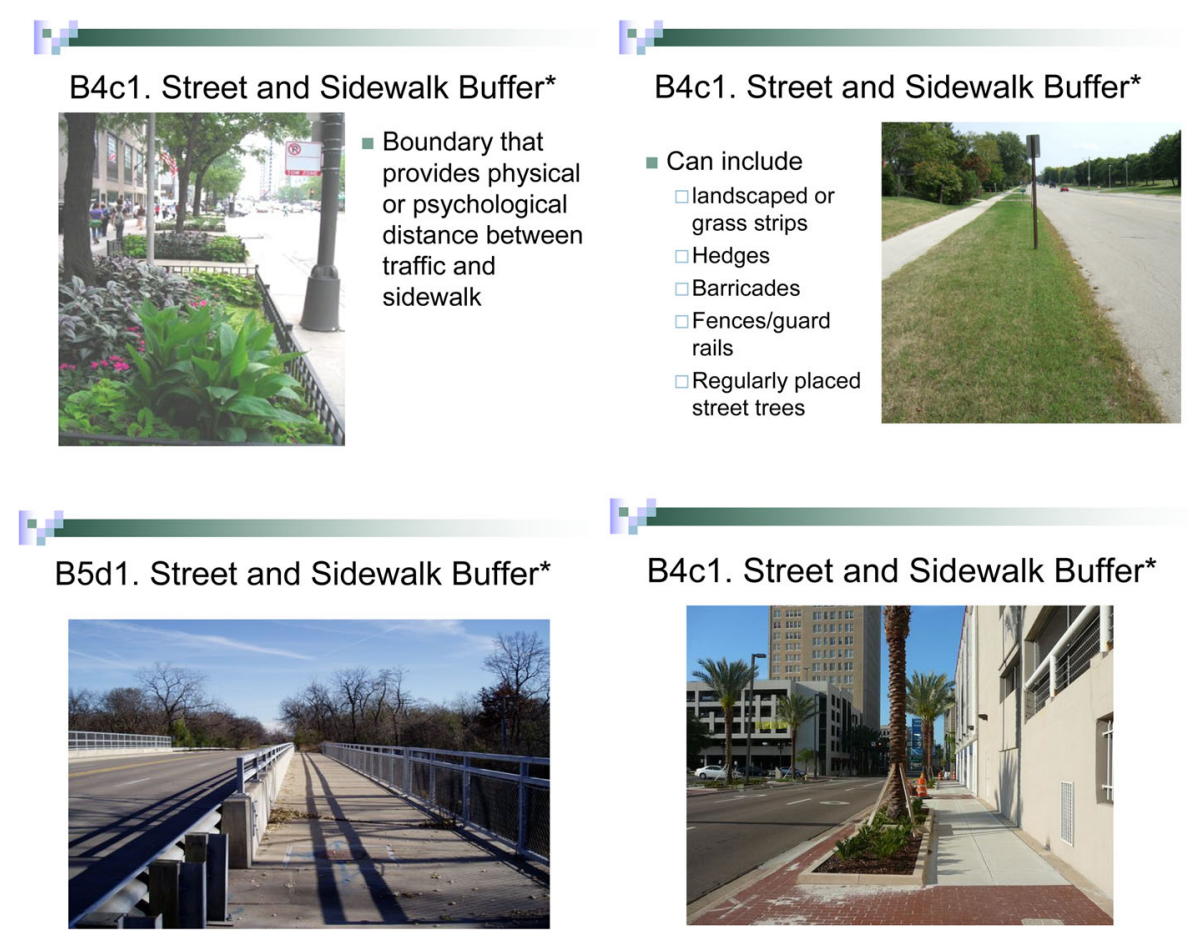

Fig. 2 Example of PHRESH SSA classroom training slides. Source: Authors' own. Legend: Street and Sidewalk Buffer: Refers to a boundary that provides physical or psychological distance between traffic and sidewalk. A street or sidewalk buffer can include landscaped or grass strips, hedges, barricades, fences/guard rails and regularly placed street trees 


\section{d. Marked Crosswalk}

Refers to a crossing point with markings for a pedestrian to cross the street segment that you are observing. These markings include painted lines, zebra striping or different road surface or paving, such as bricks. They may include flashing lights level with the street. Marked crosswalks are usually located at the end of a segment at a point of intersection but they may be present at other locations.

See the diagrams below for clarification on the items in $\mathbf{B 6}$.
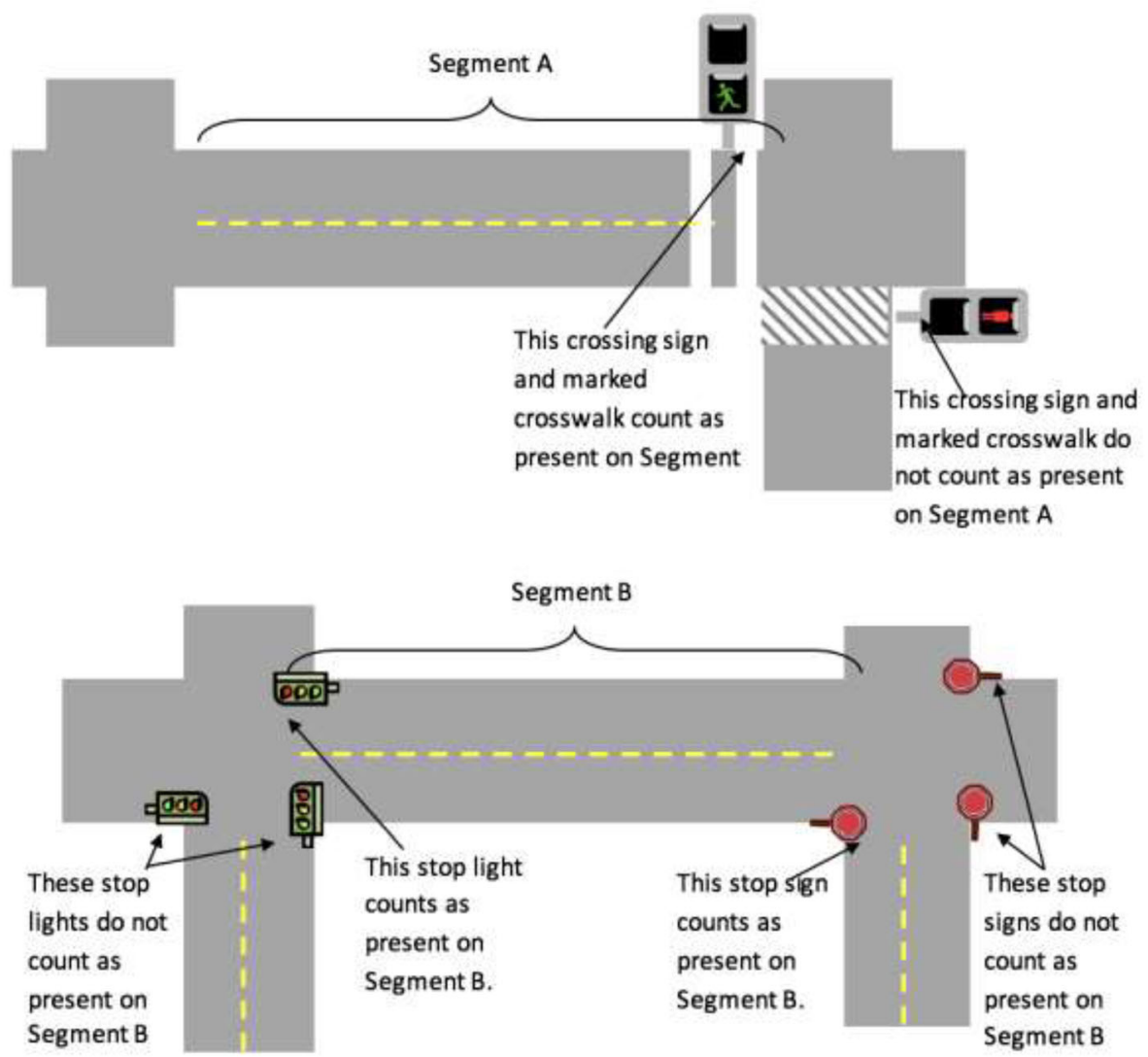

Street Segment Training Manual 2017

Page 20

Fig. 3 Example of PHRESH SSA Training Manual. Source: Authors' own. Legend: Marked Crosswalk: Refers to a crossing point with markings for a pedestrian to cross the street segment that you are observing. These markings include painted lines, zebra striping or different road surface or paving, such as bricks. They may include flashing lights level with the street. Marked crosswalks are usually located at the end of a segment at a point of intersection but they may be present at other locations

levels, we computed the PO statistic as a supplemental index of interrater reliability for all items. PO indicates the proportion of street segments where DC pairs were in exact agreement (e.g. both ratings were "no" for the same street segment). For Fig. 4, we used the following classification for PO: $\mathrm{PO}>90 \%$ indicates excellent agreement, PO between 75 and $90 \%$ indicates good agreement, and $\mathrm{PO}<75 \%$ combines moderate and fair to poor agreement $[61,62]$. Consistent with prior research, KA $>.75$ indicates excellent agreement, KA between .40 and .75 indicates intermediate to good agreement, and $\mathrm{KA}<.40$ indicates poor agreement [63]. The reliability statistics can tell us whether an audit tool item has good to excellent agreement at a single time point. On the other hand, items with good to excellent agreement at every timepoint demonstrate stability, making them appropriate to detect change.

\section{Results}

KA or PO statistics, with color-coding to indicate level of agreement, are displayed in Fig. 4. For most items, we report KA; where items are very common or rare, we report PO. In 2012, 93.8\% of items had excellent $(62.5 \%)$ or good (31.3\%) agreement. In 2015, 91.3\% of items had 


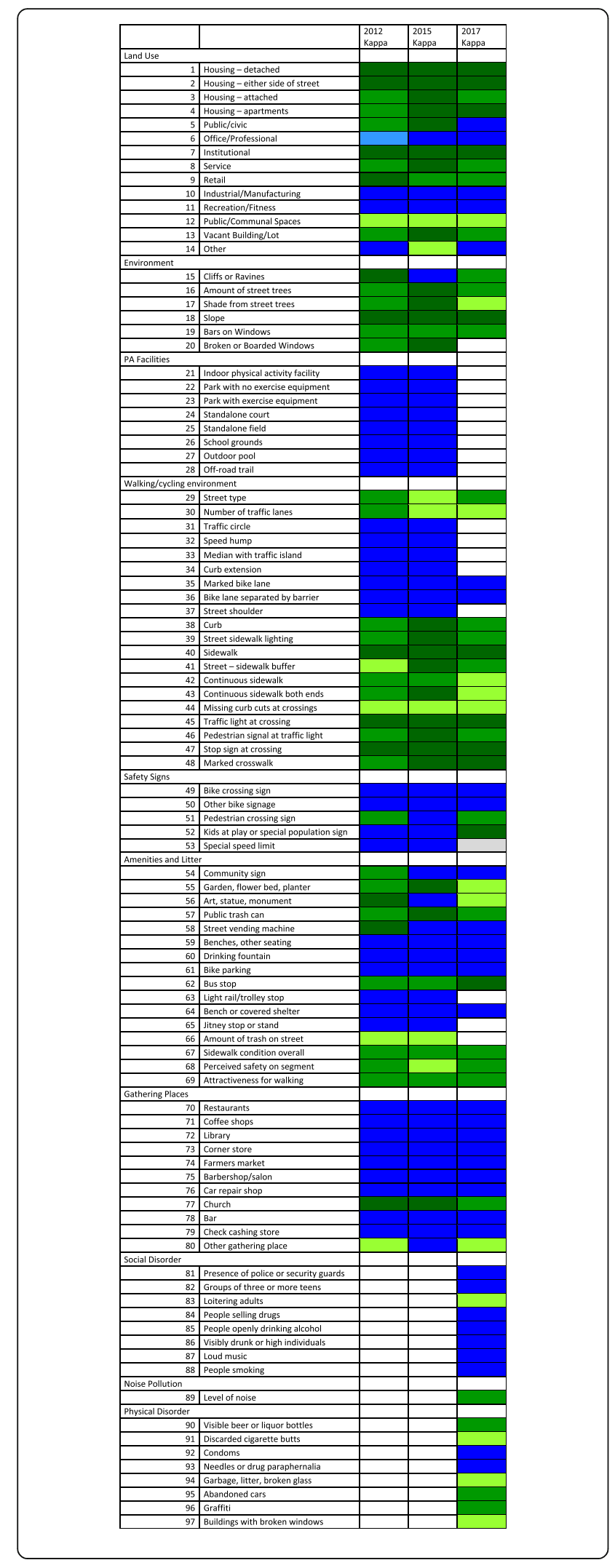

Fig. 4 Reliability of Street Segment Audit (SSA) Items. Source: Author's Calculations. Legend: Krippendorf's alpha (KA) in green or Percent inter-observer agreement $(\mathrm{PO})$ in blue are displayed. Colorcoding show levels of agreement (low, medium or high). While KA is more rigorous, when the distribution of responses for any item is skewed (i.e. a single response category with prevalence $>95 \%$ ), we cannot obtain stable estimates of the KA statistic. Therefore, we report the PO statistic for these items. Also, "na" indicates that the item was not assessed in that data collection year

excellent (83.8\%) or good (7.5\%) agreement. In 2017, $83.5 \%$ of items had excellent $(55.7 \%)$ or good $(27.8 \%)$ agreement. When assessing stability across waves, $81.4 \%$ (79 out of 97) of items had good to excellent agreement at every timepoint, making them sufficiently reliable to detect change. Prevalence statistics for individual items are shown in supplemental Table 1.

Twelve of 14 Land use mix items had good to excellent agreement while two items (public/communal spaces, other land use) had poor agreement at all waves. Five out of 6 Environment items had good to excellent agreement across waves, while one item ("do trees shade sidewalk?") had poor agreement at one of the three waves. Inspection of the individual raters' responses suggests that raters seemed to have difficulty in choosing "some" versus "many" as a response. For all 8 items in the PA facility category, there was uniformly excellent agreement at each wave.

There were 20 items in the Walking/Cycling environment category. Within the sub-category "Intersection and Crossing" including four items (traffic light, pedestrian signal at traffic light, stop sign, marked crosswalk), all had good to excellent agreement at every wave. Of the 8 items in the sub-category "Street features", four showed good to excellent agreement at every wave. Another three items ("street and sidewalk buffer", "continuous sidewalk", "sidewalk continuous at both ends between segments) showed poor agreement at one of the waves, while a fourth item ("curb cuts or ramps missing at crossing points") exhibited consistently poor agreement at every wave. The four items in the subcategory "Traffic features" ("traffic circle/roundabout", "speed hump/table", "median with traffic island", "curb extension/bulb-out") and the two cycling environment items demonstrated good to excellent agreement at every wave. The other two items in Walking/Cycling environment (street type, number of traffic lanes), showed poor agreement at either one or two of the timepoints.

There were five items in the Safety signs category; all were reliably assessed at every wave. 12 out of 16 Amenities and litter items had good to excellent agreement at every wave. Two items ("art or monument", "garden bed/planter") showed poor agreement at one of the three waves, while a third item ("amount of trash/litter on 
street") showed low agreement at every wave. Of the two more general assessments made by raters ("perceived safety", "attractiveness of segment for walking"), only one ("perceived safety") had poor agreement in one wave. Also, PO was excellent for 7 of the 8 items in the Physical activity facility category, and poor for 1 item ("other gathering place") at two of the three waves.

For 17 items in three categories, we cannot assess agreement at multiple time points because they were only measured in 2017. A single, ordinal item in Noise pollution (with 4 response categories: "no", "a little", "some" or "a lot of pollution") demonstrated good agreement. Seven of the 8 Social disorder items had excellent agreement (PO statistic >90\%) while one item ("adults loitering, congregating, or hanging out") had poor agreement $(\mathrm{PO}<75 \%)$. Three of the 8 Physical disorder items ("discarded cigarette butts", "garbage, litter, broken glass", "buildings with broken windows") had low agreement while the other five had good or excellent agreement.

\section{Discussion}

PHRESH is an ongoing study of two low-income and predominantly African American urban communities in Pittsburgh, PA. To assess whether neighborhood-level changes impact residents' health and well-being, diet, exercise, sleep, heart, and cognitive health, we conducted three assessments of the physical and social environment in the two neighborhoods over a period of five years (2012-2017). The purpose of the parent study is to identify correlates of, and the extent to which neighborhoodlevel changes, affected obesogenic behaviors such as physical activity, sleep, and heart health. In this paper, we have described our implementation methods, lessons learned, and results from repeated reliability testing of the audit tool (comprised of a standard set of items) to understand if there is stability across time to detect change in the environment over a period of five years. These are offered to inform the design and interpretation of future longitudinal studies of the physical and social environment.

Representative sampling was a critical step. Previous work had demonstrated that a $25 \%$ sample of residential street segments produced valid estimates of the built environment [54]. When assessing neighborhood-level change, one difficulty is that these changes can modify the underlying street network. Our experience suggests that secondary sources of data may include nonnegligible errors potentially due to delays in updating secondary databases. Whenever feasible (e.g. in a compact environment), we recommend careful verification of available listings of neighborhood street segments to ensure high accuracy. Also, it is necessary to update the street network at each assessment wave to capture the degree of change in the street network. To reflect actual changes in the street network, we carefully identified and sampled new street segments at each wave. When sampling new segments, systematic rules are needed. For instance, when an entire street segment was demolished, should the replacement come from the same geographic area or be sampled entirely at random? Should a newly bisected street count as two new streets, or as the same street segment from a prior wave? A changing street network meant that segment-level panel analysis was difficult; instead, it was more reasonable to identify a stable unit of analysis (e.g. a residential buffer for each study participant) to assess change.

We integrated a community engaged research framework to ensure the longevity and acceptance of PHRE SH within the study communities [43]. Our data collectors were recruited from the community, and some of the data collectors were retained across waves. However, we were not able to assess any such effects with our data. Nevertheless, thorough and consistent training of data collectors at each wave was a central feature of this work. Training at each wave employed the same methods and trainer to avoid systematic biases in ratings across waves. During training, it was important to balance classroom learning with 'live' practice. In the classroom, the use of visuals (e.g. photographs) worked well. Field practice focused on individual sections of the audit tool and presented a variety of observations. We budgeted extra time to allow data collectors to discuss questions/situations with the trainer. Thus, the training schedule needed to be flexible to allow extra time for hard-to-assess items. Furthermore, we found field practice to be the most valuable part of training. When recruiting data collectors, attention to detail was an important individual trait.

Assessment of (inter-rater) reliability of individual SSA items, using a sub-sample of segments, helped identify items that performed well at a single timepoint, and across time. A majority of SSA items (81\%) had high reliability. Low agreement indicated items that were difficult to rate objectively or with a single observation. For example, "amount of litter" or "adults loitering, congregating or hanging out" may vary even over a short window of time (e.g. a few hours or a day). In the case of trash, we re-assessed agreement for a small subset of street segments in the reliability study where two observations were conducted within hours of each other. However, the agreement for trash or litter did not improve. Items with substantial temporal variation may require multiple ratings $(>2)$ to accurately capture the average or mean rating. Certain items (e.g. perceived safety) were inherently subject to interviewer interpretation, and demonstrated lower agreement, as expected. Few neighborhood features were not easily visible across 
an entire street segment (e.g. bar on a single window, cigarette butts on the ground; garden bed/planter), or difficult to assess from the outside (e.g. public/communal space, vacant building) as was necessary according to the audit protocol.

Given these study findings, we can suggest the types of items that may be able to capture change. Consistent with previous research, more subjective measures are less reliable than more objective (observable) ones [41]; dichotomous ratings have higher reliability than ordinal response scales (although a greater number of response categories may be valuable for providing finer distinctions). Large, visible items (e.g. buildings, traffic signs) were consistently reliable. While sidewalks are an important feature of the walking environment, sidewalk conditions may change quickly over a city block, making it challenging to rate consistently. Also, rare/low prevalence features (see supplemental Table 1) did not lend themselves well to KA testing. For example, the only gathering places in these neighborhoods with prevalence above $5 \%$ were churches. If low prevalence items were readily identified, the PO statistic showed consistency in endorsing their absence.

While some features of the environment may change, there were features that are time invariant. Yet, when we compared slope ("flat", "slight hill", "steep hill") across years for a sub-group of street segments with three years of complete data, $22 \%$ of the segments had different values although slope is unlikely to change. Also, $10 \%$ of street segments were endorsed as having art/monument in 2012 , while only $2 \%$ of segments had art/monument three years later (2015.) which may point to confusion over what constitutes art. Therefore, we recommend the use of SSA items with consistently good to excellent agreement across repeat assessments to detect real change. Future studies may be able to further improve the measurement of less reliable items through detailed and intensive training or procedures (e.g., mapping out a visual area into a grid to more systematically inspect for broken windows), clearer rules and examples for determining whether something is a communal space, or by the addition of a "cannot determine" category to the form. Even subjective ratings may be improved if anchored through training or explicit item instructions (e.g. $1=$ a place where you would not feel physically at risk of violence from another person if walking alone in daylight, etc.), and by use of multiple raters to reduce individual rater idiosyncrasies.

In our knowledge, this article is the first to conduct repeated assessments of the built and social environment to assess change. We found the PHRESH study's SSA tool to be reliable and practical to implement, with an average of $13 \mathrm{~min}$ required per street segment, that data collectors found easy to use. The audit tool provided rich and detailed data on environmental features, and change over time, which is important for the exploration of cross-sectional and longitudinal relationships between neighborhood features and health outcomes. The compact nature of our study neighborhoods suggests a need to test this audit tool in neighborhoods with greater variation, as certain items exhibited low or zero prevalence in the study neighborhoods. Future research might want to evaluate reliability separately if comparing change across neighborhoods for a natural experiment or intervention study. Our sample sizes for the reliability subsample were only sufficient to assess overall reliability by pooling sample across neighborhoods. Future study design can consider sample allocation so that the two neighborhoods (with and without intervention) are assessed with equal reliability. Also, additional steps are necessary to develop and validate summary measures or indices that capture meaningful constructs (e.g. walkability, incivilities) that may be predictors of health outcomes. If valid indices of environmental features can be derived, they will be useful in guiding public policy and urban planning in the redesign of built environments to promote health.

\section{Conclusion}

This paper presents lessons learned from repeat administrations of a comprehensive audit tool for direct observation of the environment. Longitudinal assessments required consistency of methods and data collector training to minimize systematic differences across time. Inter-rater reliability testing conducted at each time point suggested that most items were consistently reliable and were useful to assess changes in the environment. Typically, items with poor reliability were either difficult to rate or subjective in nature, making them less useful to detect real change over time. The PHRESHSSA tool proved to be a generally reliable and practical instrument for collecting data that trained observers found easy to use.

\section{Supplementary information}

Supplementary information accompanies this paper at https://doi.org/10. 1186/s12889-020-09424-8.

\section{Additional file 1.}

\section{Abbreviations}

BTG-COMP: Bridging the Gap/Community Obesity Measures Project; GSV: Google Street View; GIS: Geographic information systems; SSA: Street Segment Audit Tool; SPACES: Systematic Pedestrian and Cycling

Environmental Scan; SLU: St. Louis Analytic Audit Tool and Checklist; PEDS: Pedestrian Environment Data Scan; PHRESH: Pittsburgh Hill/

Homewood Research on Neighborhood Change and Health;

KA: Krippendorff's alpha; PO: Percent observer agreement;

ESRI: Environmental Systems Research Institute 


\section{Acknowledgements}

We thank Ms. La'vette Wagner, Mr. Alvin Nugroho, the data collectors and the community advisory board. We also thank Dr. Jaana Myllyluoma of John Hopkins Carey Business School for assistance with developing the PHRESH training manual, including Figs. 1 and 2, and conducting training of the street segment audit tool.

\section{Authors' contributions}

MGD, GH and RC worked on study conception; MGD, GH, and AR developed the methodology. JS compiled the literature review and managed data collection, while $\mathrm{GH}$ took charge of data curation and programming. Funding acquisition was completed by WT and TD, and the audit tool development was carried out by WT, NC, AR and TD. MGD, GH and JS provided the writing for the original draft, and all authors contributed to the reviewing and editing process. The author(s) read and approved the final manuscript.

\section{Funding}

This research including design and data collection of the street segment audits; data analysis; and writing of the manuscript was supported by the National Cancer Institute (grant number R01 CA149105) and the National Heart Lung Blood Institute (grants number R01 HL122460 and HL131531).

\section{Availability of data and materials}

The datasets used and/or analyzed during the current study are available from the corresponding author on reasonable request.

\section{Ethics approval and consent to participate}

Not applicable.

\section{Consent for publication}

Not applicable.

\section{Competing interests}

The authors have indicated they have no financial relationships relevant to this article to disclose.

\section{Author details}

1RAND Corporation Santa Monica, 1776 Main St, Santa Monica, CA 90401, USA. ${ }^{2}$ RAND Corporation Pittsburgh, 4570 Fifth Ave \#600, Pittsburgh, PA 15213, USA. ${ }^{3}$ The Pittsburgh Foundation, Five PPG Place, Suite 250, Pittsburgh, PA 15222, USA. ${ }^{4}$ University of Michigan, 1402 Washington Heights, Ann Arbor, Ml 48109-2013, USA.

\section{Received: 5 February 2020 Accepted: 23 August 2020}

\section{Published online: 07 October 2020}

\section{References}

1. Caspi CE, Sorensen G, Subramanian S, Kawachi I. The local food environment and diet: a systematic review. Health Place. 2012;18(5):1172-87.

2. Giskes K, van Lenthe F, Avendano-Pabon M, Brug J. A systematic review of environmental factors and obesogenic dietary intakes among adults: are we getting closer to understanding obesogenic environments? Obes Rev. 2011; 12(5):e95-e106.

3. Macintyre S, Ellaway A. Neighborhoods and health: an overview. Neighborhoods Health. 2003;20:42.

4. Sampson RJ, Morenoff JD, Gannon-Rowley T. Assessing "neighborhood effects": social processes and new directions in research. Annu Rev Social. 2002;28(1):443-78.

5. Borrell LN, Diez Roux AV, Rose K, Catellier D, Clark BL. Neighbourhood characteristics and mortality in the atherosclerosis risk in communities study. Int J Epidemiol. 2004;33(2):398-407.

6. Diez Roux AV, Mujahid MS, Hirsch JA, Moore K, Moore LV. The impact of neighborhoods on CV risk. Glob Heart. 2016;11(3):353-63.

7. Miranda ML, Messer LC, Kroeger GL. Associations between the quality of the residential built environment and pregnancy outcomes among women in North Carolina. Environ Health Perspect. 2011;120(3):471-7.

8. Troxel WM, Shih RA, Ewing B, Tucker JS, Nugroho A, D'Amico EJ. Examination of neighborhood disadvantage and sleep in a multi-ethnic cohort of adolescents. Health Place. 2017;45:39-45.
9. Wood L, Hooper P, Foster S, Bull F. Public green spaces and positive mental health-investigating the relationship between access, quantity and types of parks and mental wellbeing. Health Place. 2017;48:63-71.

10. Bauman AE, Reis RS, Sallis JF, Wells JC, Loos RJ, Martin BW, et al. Correlates of physical activity: why are some people physically active and others not? Lancet. 2012;380(9838):258-71.

11. Coombes $E$, Jones AP, Hillsdon M. The relationship of physical activity and overweight to objectively measured green space accessibility and use. Soc Sci Med. 2010;70(6):816-22.

12. Heath GW, Brownson RC, Kruger J, Miles R, Powell KE, Ramsey LT, et al. The effectiveness of urban design and land use and transport policies and practices to increase physical activity: a systematic review. J Phys Act Health. 2006;3(s1):S55-76

13. Mozaffarian D, Afshin A, Benowitz NL, Bittner V, Daniels SR, Franch HA, et al. Population approaches to improve diet, physical activity, and smoking habits: a scientific statement from the American Heart Association. Circulation. 2012;126(12):1514-63.

14. Saelens BE, Sallis JF, Black JB, Chen D. Neighborhood-based differences in physical activity: an environment scale evaluation. Am J Public Health. 2003; 93(9):1552-8.

15. Van Cauwenberg J, De Bourdeaudhuij I, De Meester F, Van Dyck D, Salmon J, Clarys $P$, et al. Relationship between the physical environment and physical activity in older adults: a systematic review. Health Place. 2011;17(2):458-69.

16. Capppuccio FP, Miller MA, Lockley SW, Rajaratnam SMW. Sleep, health, and society: From aetiology to public health, Second edition: Oxford University Press; 2018. https://doi.org/10.1093/oso/9780198778240.001.0001.

17. Johnson DA, Hirsch JA, Moore KA, Redline S, Diez Roux AV. Associations between the built environment and objective measures of sleep: the multiethnic study of atherosclerosis. Am J Epidemiol. 2018;187(5):941-50.

18. Laurent JGC, Allen JG, Spengler JD. The built environment and sleep. Sleep, health, and society: From Aetiology to public health, Second edition: Oxford University Press; 2018. https://doi.org/10.1093/oso/9780198778240.003.0023.

19. Warburton DE, Nicol CW, Bredin SS. Health benefits of physical activity: the evidence. Can Med Assoc J. 2006;174(6):801-9.

20. Warburton DER, Bredin SSD. Health benefits of physical activity: a systematic review of current systematic reviews. Curr Opin Cardiol. 2017;32(5):541-56.

21. Levine JA. Poverty and obesity in the U.S. Diabetes. 2011;60(11):2667-8.

22. Estabrooks PA, Lee RE, Gyurcsik NC. Resources for physical activity participation: does availability and accessibility differ by neighborhood socioeconomic status? Ann Behav Med. 2003;25(2):100-4

23. Gordon-Larsen P, Nelson MC, Page P, Popkin BM. Inequality in the built environment underlies key health disparities in physical activity and obesity. Pediatrics. 2006;117(2):417-24.

24. Troxel WM, DeSantis A, Richardson AS, Beckman R, Ghosh-Dastidar B, Nugroho A, et al. Neighborhood disadvantage is associated with actigraphy-assessed sleep continuity and short sleep duration. Sleep. 2019; 42(3):zsy250.

25. Sallis JF, Bauman A, Pratt M. Environmental and policy interventions to promote physical activity. Am J Prev Med. 1998;15(4):379-97.

26. Boarnet MG, Forsyth A, Day K, Oakes JM. The street level built environment and physical activity and walking: results of a predictive validity study for the Irvine Minnesota inventory. Environ Behav. 2011;43(6):735-75.

27. Brownson RC, Hoehner CM, Day K, Forsyth A, Sallis JF. Measuring the built environment for physical activity: state of the science. Am J Prev Med. 2009; 36(4 Suppl):S99-123 e12.

28. Moudon AV, Lee C. Walking and bicycling: an evaluation of environmental audit instruments. Am J Health Promot. 2003;18(1):21-37.

29. Caughy MO, O'Campo PJ, Patterson J. A brief observational measure for urban neighborhoods. Health Place. 2001;7(3):225-36.

30. Laraia BA, Messer L, Kaufman JS, Dole N, Caughy M, O'Campo P, et al. Direct observation of neighborhood attributes in an urban area of the US south: characterizing the social context of pregnancy. Int J Health Geogr. 2006;5(1):11.

31. Raudenbush SW, Sampson RJ. Ecometrics: toward a science of assessing ecological settings, with application to the systematic social observation of neighborhoods. Sociol Methodol. 1999;29(1):1-41.

32. Brownson RC, Hoehner CM, Brennan LK, Cook RA, Elliott MB, McMullen KM. Reliability of 2 instruments for auditing the environment for physical activity. J Phys Act Health. 2004;1(3):191-208.

33. Kelly CM, Wilson JS, Baker EA, Miller DK, Schootman M. Using Google Street View to audit the built environment: inter-rater reliability results. Ann Behav Med. 2012;45(suppl_1):S108-S12. 
34. Twardzik E, Antonakos C, Baiers R, Dubowitz T, Clarke P, Colabianchi N Validity of environmental audits using GigaPan ${ }^{\oplus}$ and Google earth technology. Int J Health Geogr. 2018;17(1):26.

35. Clarke P, Ailshire J, Melendez R, Bader M, Morenoff J. Using Google earth to conduct a neighborhood audit: reliability of a virtual audit instrument. Health Place. 2010;16(6):1224-9.

36. Taylor BT, Fernando P, Bauman AE, Williamson A, Craig JC, Redman S. Measuring the quality of public open space using Google earth. Am J Prev Med. 2011;40(2):105-12.

37. PHRESH. PHRESH: Pittsburgh Hill/Homewood Researach on Neighborhood Change and Health no date. 2020. Available from: https://www.rand.org/wellbeing/community-health-and-environmental-policy/projects/phresh.html.

38. Pikora TJ, Bull FC, Jamrozik K, Knuiman M, Giles-Corti B, Donovan RJ. Developing a reliable audit instrument to measure the physical environment for physical activity. Am J Prev Med. 2002;23(3):187-94.

39. Brownson RC, Chang JJ, Eyler AA, Ainsworth BE, Kirtland KA, Saelens BE, et al. Measuring the environment for friendliness toward physical activity: a comparison of the reliability of 3 questionnaires. Am J Public Health. 2004; 94(3):473-83.

40. Hoehner CM, Ivy A, Ramirez LK, Handy S, Brownson RC. Active neighborhood checklist: a user-friendly and reliable tool for assessing activity friendliness. Am J Health Promot. 2007;21(6):534-7.

41. Clifton KJ, Smith ADL, Rodriguez D. The development and testing of an audit for the pedestrian environment. Landsc Urban Plan. 2007:80(1-2):95110.

42. Shoukri MM. Measures of interobserver agreement and reliability, Second edition. Chapman \& Hall/CRC press; 2011.

43. Dubowitz T, Ncube C, Leuschner K, Tharp-Gilliam S. A natural experiment opportunity in two low-income urban food desert communities: research design, community engagement methods, and baseline results. Health Educ Behav. 2015:42(1_suppl):87S-96S.

44. Dubowitz T, Zenk SN, Ghosh-Dastidar B, Cohen DA, Beckman R, Hunter G, et al. Healthy food access for urban food desert residents: examination of the food environment, food purchasing practices, diet and BMI. Public Health Nutr. 2015;18(12):2220-30.

45. Kelly CM, Schootman M, Baker EA, Barnidge EK, Lemes A. The association of sidewalk walkability and physical disorder with area-level race and poverty. J Epidemiol Community Health. 2007;61(11):978-83.

46. Slater SJ, Nicholson L, Chriqui J, Barker DC, Chaloupka FJ, Johnston LD. Walkable communities and adolescent weight. Am J Prev Med. 2013;44(2): 164-8.

47. Zenk SN, Slater S, Rashid S. Collecting contextual health survey data using systematic observation. In: Handbook of Health Survey Methods John Wiley and Sons, Inc; 2015. p. 421-45.

48. Day K, Boarnet M, Alfonzo M, Forsyth A. The Irvine-Minnesota inventory to measure built environments: development. Am J Prev Med. 2006; 30(2):144-52.

49. Emery J, Crump C, Bors P. Reliability and validity of two instruments designed to assess the walking and bicycling suitability of sidewalks and roads. Am J Health Promot. 2003;18(1):38-46.

50. Slater SJ, Ewing R, Powell LM, Chaloupka FJ, Johnston LD, O'Malley PM. The association between community physical activity settings and youth physical activity, obesity, and body mass index. J Adolesc Health. 2010;47(5): 496-503.

51. Brownson RC, Brennan Ramirez LK, Hoehner CM, Cook RA. Analytic audit tool and checklist audit tool; 2003.

52. Caspi CE, Kawachi I, Subramanian S, Tucker-Seeley R, Sorensen G. The social environment and walking behavior among low-income housing residents. Soc Sci Med. 2013;80:76-84.

53. Sampson RJ, Raudenbush SW. Systematic social observation of public spaces: a new look at disorder in urban neighborhoods. Am J Sociol. 1999; 105(3):603-51.

54. McMillan TE, Cubbin C, Parmenter B, Medina AV, Lee RE. Neighborhood sampling: how many streets must an auditor walk? Int J Behav Nutr Phys Act. 2010;7(1):20

55. Feinstein AR, Cicchetti DV. High agreement but low kappa: I. the problems of two paradoxes. J Clin Epidemiol. 1990;43(6):543-9.

56. Cicchetti DV, Feinstein AR. High agreement but low kappa: II. Resolving the paradoxes. J Clin Epidemiol. 1990;43(6):551-8.

57. Hayes AF, Krippendorff K. Answering the call for a standard reliability measure for coding data. Commun Methods Meas. 2007;1(1):77-89.
58. Krippendorff K. Estimating the reliability, systematic error and random error of interval data. Educ Psychol Meas. 1970;30(1):61-70.

59. Krippendorff K. Content analysis. An introduction to its methodology, Third edition. Thousand Oaks: Sage Publications; 2013.

60. Krippendorff K. Reliability of binary attribute data. Biometrika. 1978;34:142-4.

61. Hartmann DP. Considerations in the choice of interobserver reliability estimates. J Appl Behav Anal. 1977;10(1):103-16.

62. Stemler SE. A comparison of consensus, consistency, and measurement approaches to estimating interrater reliability. Pract Assess Res Eval. 2004; 9(4):1-19.

63. Fleiss $\mathrm{JL}$. Balanced incomplete block designs for inter-rater reliability studies. Appl Psychol Meas. 1981;5(1):105-12.

\section{Publisher's Note}

Springer Nature remains neutral with regard to jurisdictional claims in published maps and institutional affiliations.
Ready to submit your research? Choose BMC and benefit from:

- fast, convenient online submission

- thorough peer review by experienced researchers in your field

- rapid publication on acceptance

- support for research data, including large and complex data types

- gold Open Access which fosters wider collaboration and increased citations

- maximum visibility for your research: over 100M website views per year

At BMC, research is always in progress.

Learn more biomedcentral.com/submissions 